\title{
An anatomical variation of the third common digital nerve and recurrent motor branch of the median nerve
}

\author{
Emre Demircay, Serdar Kabatas ${ }^{1}$, Tufan Cansever $^{1}$, Cem Yilmaz ${ }^{1}$ \\ Departments of Orthopaedics and ${ }^{1}$ Neurosurgery, Baskent University, Ankara, Turkey
}

\begin{abstract}
Carpal tunnel syndrome (CTS) is an entrapment neuropathy where the median nerve is compressed in the carpal canal. There are many variations of the distal branches of the median nerve at the wrist. Anatomical variations of this nerve have fundamental clinical importance to prevent injuries, especially during limited open or endoscopic surgical procedures. A case is presented of an anomalous course of the recurrent motor branch of the median nerve and high division of the third common digital nerve seen in a limited open carpal tunnel release.
\end{abstract}

Address for correspondence:

Dr. Serdar Kabatas,

Baskent University Istanbul Hospital,

Department of Neurosurgery,

Oymaci Sokak No: 7 34662,

Altunizade, Istanbul, Turkey.

E-mail: kabatasserdar@hotmail.com

DOI: $10.4103 / 0028-3886.53281$
Key words: Anatomical variation, carpal tunnel syndrome, median nerve

\section{Introduction}

Carpal tunnel syndrome (CTS). is the most common entrapment neuropathy encountered in clinical practice. ${ }^{[1,2]}$ Variations of the median nerve and the adjacent structures may be seen clinically or observed during surgery/cadaveric dissection. ${ }^{[3]}$ We recently encountered an unusual anatomic variation of median nerve at the wrist during the surgery.

\section{Case Report}

A 48-year-old woman underwent surgery for CTS in her right hand, dominant hand for the patient. She had no underlying medical disorder. Surgery was performed through a limited open approach. When transverse carpal ligament (TCL) was transected, it was seen that the median nerve was divided to third common digital nerve and to the recurrent motor branch proximal to the distal end of the TCL, and an accessory transligamentous thenar branch about $1 \mathrm{~mm}$ in diameter could be identified just proximal to the division [Figure 1a and $b$ ]. The incision was extended when the anatomic variation was seen. Decompression of the nerves was verified, and the incision was not extended beyond what was required for the carpal tunnel release.

\section{Discussion}

Varying results have been reported on the prevalence of median nerve anomalies ${ }^{[2]}$ Lindley and Kleinert observed $1 \%$ (five hands) median nerve or its palmar cutaneous branch or motor branch anomalies during the course of 526 elective carpal tunnel releases in one surgeon's practice. ${ }^{[4]}$ Lanz classified variations of the median nerve into four groups: Group I, variations of the course of the motor branch; group II, accessory branches of the median nerve at the distal carpal tunnel; group III, high division of the median nerve; and group IV, accessory branches proximal to the carpal tunnel. Thenar motor branch can be further categorized due to its origin - ulnar, radial, or volar - or by the relationship of the TCL to the thenar motor branch - extraligamantous, subligamantous, transligamantous, or intraligamantous ${ }^{[2]}$ Furthermore, Engineer et al. identified three specific anatomic variations for the origin of the third common digital nerve: Type I originating proximal to the distal edge of the TCL (15\%); type II originating distal to the TCL but proximal to the superficial palmar arch (70\%); and type III originating distal to the TCL and at/or distal to the superficial palmar arch $(15 \%) .^{[5]}$

Steinberg et al. dissected 46 hands and in 10 hands they found an accessory branch of the median nerve, piercing the lateral carpal ligament $3-6 \mathrm{~mm}$ distal to the proximal 
edge of the tunnel. The branch was approximately $1 \mathrm{~mm}$ wide, leaving the radial or volar side of the median nerve at a right angle. They considered it as a sensory branch due to its size and course. ${ }^{[6]}$ This accessory branch was similiar to the one in our case except that we observed the nerve in distal part of the tunnel and the median nerve was divided to its branches under the TCL.

Median nerve variation in our case seems to fit best into Lanz group II - an accessory branch distal to the carpal tunnel - and engineer type I - third common digital nerve (terminal branches) originating proximal to the distal edge of the TCL. We did not dissect the accessory transligamantous nerve because it was beyond the necessity of the operation. We suggest it is a sensory branch as Steinberg et al. concluded in their series due to its small diameter.

It is important to identify the anatomic variations of the median nerve for the safe and effective decompression of the nerve [Table 1]. There are few, if any, clinical and electrophysiological clues indicating anatomic variations. The anastomosis between the median and ulnar nerve in the forearm, known as Martin-Gruber anastomosis, is of crucial importance in the clinical evaluation of nerve injuries of the median and ulnar nerves, as well as in accurate interpretation of nerve conduction velocity of these nerves, especially in association with CTS. ${ }^{[7]}$ Furthermore, several anatomical and electrophysiological studies demonstrated the possibility of an unlar-to-median anastomosis in the distal forearm 'reversed Martin-Gruber anastomosis or Marinacci communication' ${ }^{[8]}$ Iatrogenic injury of this nerve communication may be misdiagnosed as a thenar branch lesion. ${ }^{[9]}$ Thus, detailed preoperative electrophysiological studies should be necessary to avoid nerve injuries in the carpal tunnel release.

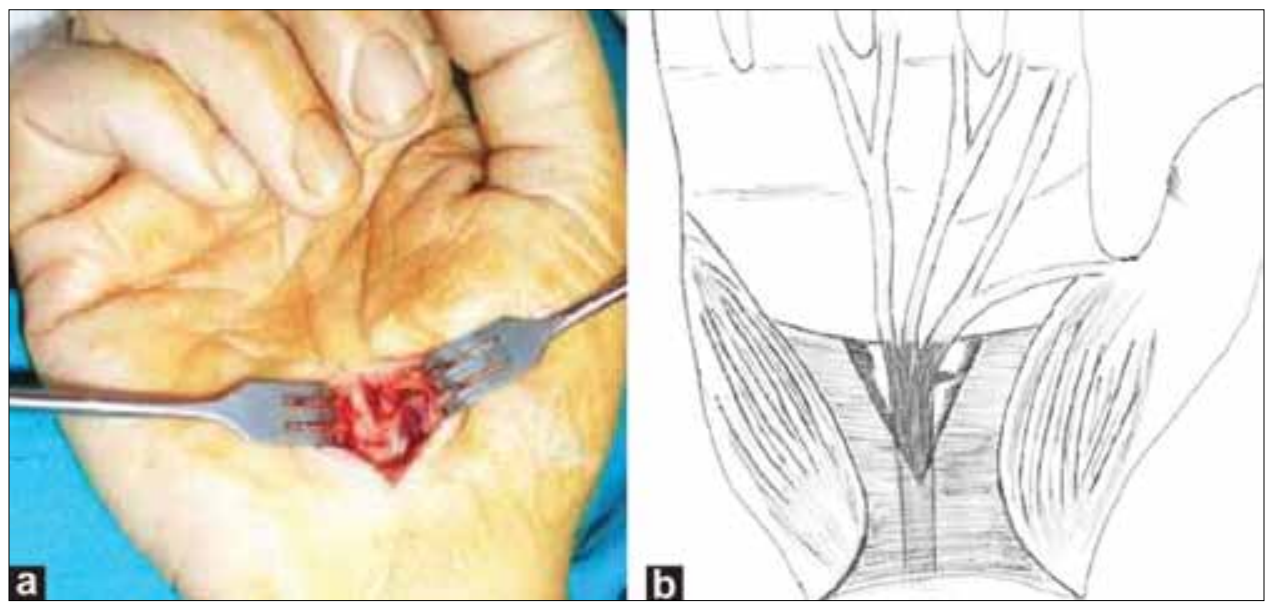

Figure 1: Intraoperative view (a) and illustration (b) demonstrating the median nerve divided to third common digital nerve and to the recurrent motor branch proximal to the distal end of the transverse carpal ligament, and an accessory transligamentous thenar branch approxiametly $1 \mathrm{~mm}$ in diameter was identified just proximal to the division

\begin{tabular}{|c|c|c|c|}
\hline \multirow[t]{4}{*}{ Group I } & $\begin{array}{l}\text { Variations of the course of } \\
\text { the thenar branch }\end{array}$ & Extraligamantous & \\
\hline & & Subligamantous & Increased risk of division if not visualized \\
\hline & & Transligamantous & $\begin{array}{l}\text { Increased risk of division if not visualized } \\
\text { seperate release may be needed }\end{array}$ \\
\hline & & Intraligamantous & $\begin{array}{l}\text { Increased risk of division if not visualized } \\
\text { seperate release is needed }\end{array}$ \\
\hline Group II & \multicolumn{2}{|c|}{ Accessory branches of the median nerve at the distal portion of the carpal tunnel } & Increased risk of division if not visualized \\
\hline Group III & \multicolumn{2}{|c|}{ High division of the median nerve } & Increased risk of division if not visualized \\
\hline Group IV & \multicolumn{2}{|c|}{ Accessory branches proximal to the carpal tunnel } & Increased risk of division if not visualized \\
\hline Engineer type I & \multicolumn{2}{|c|}{ TCDN originating proximal to the distal edge of the TCL } & Increased risk of division if not visualized \\
\hline Engineer type II & \multirow{2}{*}{\multicolumn{2}{|c|}{$\begin{array}{l}\text { TCDN originating distal to the TCL but proximal to the the superficial palmar arch } \\
\text { TCDN originating distal to the TCL and at or distal to the the superficial palmar arch }\end{array}$}} & Increased risk of division if not visualized \\
\hline Engineer type III & & & $\begin{array}{l}\text { Increased risk of division particularly in endo- } \\
\text { scopic procedures using distal portal (Chow } \\
\text { technique) }\end{array}$ \\
\hline \multirow{3}{*}{$\begin{array}{l}\text { Thenar motor } \\
\text { branch }\end{array}$} & \multicolumn{2}{|l|}{ Radial } & \\
\hline & \multicolumn{2}{|l|}{ Volar } & \\
\hline & \multicolumn{2}{|l|}{ Ulnar } & Increased risk of division if not visualized \\
\hline
\end{tabular}

TCDN - Third common digital nerve; TCL - Transverse carpal ligament 
Although the anatomical variations are recently classified, there are still different kinds of anomalies that can be seen. Thus, surgeons should take such anatomical variations into consideration in order to plan appropriate surgical approaches.

\section{References}

1. Wardle NS, Pourgiezis N, Ashwood N, Bain GI. A history of carpal tunnel syndrome. Br J Hosp Med (Lond) 2008;69:254-9.

2. Lanz U. Anatomical variations of the median nerve in the carpal tunnel. J Hand Surg [Am] 1977;2:44-53.

3. Lee WP, Strickland JW. Safe carpal tunnel release via a limited palmar incision. Plast Reconstr Surg 1998;101:418-24.

4. Lindley SG, Kleinert JM. Prevalence of anatomic variations encountered in elective carpal tunnel release. J Hand Surg [Am] 2003;28:849-55.
5. Engineer NJ, Hazani R, Mowlavi A, Neumeister MW, Lee WPA, Wilhelmi BJ. Variations in the Anatomy of the Third Common Digital Nerve and Landmarks to Avoid Injury to the Third Common Digital Nerve With Carpal Tunnel Release. Eplasty 2008;8:e51.

6. Steinberg EL, Luger E, Taitz C, Arensburg B. Anatomic variant of the median nerve in the carpal tunnel. Clin Orthop Relat Res 1998;352:128-30.

7. Sarikcioglu L, Sindel M, Ozkaynak S, Aydin H. Median and ulnar nerve communication in the forearm: An anatomical and electrophysiological study. Med Sci Monit 2003;9:BR351-6.

8. Golovchinsky V. Ulnar-to-median anastomosis and its role in the diagnosis of lesions of the median nerve at the elbow and the wrist Electromyogr Clin Neurophysiol 1990;30:31-4.

9. Stancić MF, Burgić N, Mićović V. Marinacci communication. Case report. J Neurosurg 2000;92:860-2.

Accepted on 12-03-2009

Source of Support: Nil, Conflict of Interest: None declared. 